CLINICAL STUDY

\title{
Upper airway obstruction in patients with endothoracic goiter enlargement: no relationship between flow-volume loops and radiological tests
}

\author{
M Albareda, J Viguera ${ }^{1}$, C Santiveri ${ }^{2}$, P Lozano $^{3}$, A Mestrón, N Bengoa, R Calvet ${ }^{2}$, A Roger ${ }^{4}$, D Pardillo ${ }^{4}$, E Delgado $^{3}$ \\ and Ll Vila \\ Endocrinology and Nutrition Service, Hospital Moisès Broggi, Saint Joan Despi, 08970 Barcelona, Spain, ${ }^{1}$ Endocrinology and Nutrition Service, \\ ${ }^{2}$ Pneumology Service, Hospital Dos de Maig, 08025 Barcelona, Spain, ${ }^{3}$ Centro diagnóstico de Pedralbas, Dos de Maig Unity, CETIR, O9025 Barcelona, \\ Spain and ${ }^{4}$ Pneumology Service, Hospital Moisès Broggi, Saint Joan Despi, 08970 Barcelona, Spain \\ (Correspondence should be addressed to Ll Vila; Email: lluis.vila@sanitatintegral.org)
}

\begin{abstract}
Background: In about 16-85\% of subjects with goiter, upper airway obstruction (UAO) is observed. This percentage is higher in patients affected by goiter with endothoracic enlargement. UAO is an indication for surgery. Visual analysis of flow-volume loops (FVL) are the best indicators for UAO, although various studies using clinical and radiological parameters have observed no correlation. Objective: To evaluate the presence of UAO in patients with endothoracic goiter enlargement and the relationship between the FVL with the observed symptoms and the measurements obtained by computed tomography (CT).

Subjects: Subjects with endothoracic goiter enlargement participated in the study.

Design: i) Symptom questionnaire (dysphagia, dyspnea, cough, oppression, dysphonia, and worsened symptoms when prone); ii) analysis: TSH and free thyroxine; iii) cervical ultrasound; iv) cervicalthoracic CT (measurements of area and diameter in the area of maximum stenosis and at $2 \mathrm{~cm}$ from the carina); v) chest radiography and vi) forced spirometry: visual analysis of FVL morphology and the maximum forced expiratory volume in $1 \mathrm{~s}\left(\mathrm{FEV}_{1}\right)$, forced expiratory flow at $50 \%$ vital capacity/forced inspiratory flow at $50 \%$ vital capacity and $\mathrm{FEV}_{1} /$ peak expiratory flow parameters.

Results: Fifty subjects participated in the study: 11 men/39 women, median age 73.8 years (43.76-88.43). UAO was diagnosed in 13 cases (26\%, confidence interval: $14.6-40.3 \%)$ and 27 subjects $(54 \%)$ presented symptoms suggesting goiter compression. No clinical or radiological variables showed the presence of UAO.

Conclusions: The frequency of UAO in subjects affected by goiter with endothoracic enlargement was lower than that described for goiter patients, and there were no clinical or radiological indicators to establish its presence.
\end{abstract}

European Journal of Endocrinology 163 665-669

\section{Introduction}

Upper airway obstruction (UAO) is one of the complications, which may appear in subjects with goiter. Prevalence according to existing studies ranges between 16 and $85 \%(1-5)$, and this wide range may be due to the differences in inclusion criteria of the population in question (6).

Clinical or functional signs of UAO in subjects with goiter are considered to be indications for surgical treatment, including in elderly patients $(2,3,6)$; yet $<50 \%$ of these patients present symptoms $(2,7)$, which suggests that clinical history seldom predicts the presence of UAO. Furthermore, the correlation between radiological indices and flow-volume loops (FVL) in subjects with UAO due to goiter enlargement is low $(5,8)$, and there also exists discrepancies between radiological test and clinical test correlations (9).

UAO is even more prevalent in patients with endothoracic goiter (5) and ranges between 2.3 and $30 \%$ mainly due to the variability of criteria used in its definition (9). Computed tomography (CT) is the most efficient test, due to its sensitivity, to diagnose these goiters $(10,11)$.

Given that the most probable treatment for patients with goiter and UAO is surgery, a step not without its risks, correct diagnosis is crucial. Forced spirometry is currently the simplest method available to establish the presence of UAO $(2,5)$. The evaluation of FVL obtained during maximum forced spirometry inspirations and 
expirations by an expert is the most sensitive and specific test in determining UAO (5). Functional respiratory tests after surgery show an improvement in over $90 \%$ of all cases $(3,5)$. However, the degree of patient effort and the degree of cooperation added to observer experience are associated with errors in the interpretation of FVL.

The objectives of this study were to evaluate the frequency of UAO in patients with downward enlargement of the goiter as well as to weigh the relationship between the presence of UAO with the clinical and tracheal compression measurements calculated by CT.

\section{Subjects and methods}

In a prospective observational transversal study, patients with intrathoracic enlargement goiters attending the Endocrinology Department at Dos de Maig Hospital in Barcelona (2nd tier hospital) from January 2000 to December 2003 were included. All patients whose goiter exceeded the cervicothoracic isthmus and below the subclavian vessels in CT scans were included (12).

The study protocol consisted of the following parameters: i) a questionnaire: reason for consultation (accidental discovery through chest radiography or CT, full clinical history, and goiter study), length of evolution, and presence of clinical compressive symptoms (dyspnea, dysphagia, cough, oppression, dysphonia, and worsening of symptoms when lying prone); ii) analysis: measurement of TSH and free thyroxine $\left(\mathrm{T}_{4}\right)$; iii) cervical ultrasound: type of goiter (diffuse, multinodular, and predominating node goiter); iv) fine needle aspiration when nodules were present or with ultrasound criteria suspecting malignancy; v) CT: confirmation of the presence of endothoracic enlargement (12), presence of tracheal stenosis, and measurements of tracheal area and diameter at $2 \mathrm{~cm}$ from the carina and in the area of maximum stenosis. Afterward, the quotient between diameters of the carina and the stenosis was calculated, as well as the area between the two. Reasons for using the measurement at $2 \mathrm{~cm}$ from the carina as reference point are described in the article by Melissant et al. (8) which states that in the first place, there are no healthy control values due to wide intra-individual variables and their lack of correlation to anthropometric data. Secondly, there are slight differences in the levels of the trachea, and intraindividual variables between the transverse dimensions in these different levels are minor. The diameter of the trachea at $2 \mathrm{~cm}$ from the carina may be $10 \%$ greater than from the middle part, and this relationship is highly reproducible among the subjects; vi) anteroposterior chest X-ray, with an evaluation of the presence of deviation or tracheal stenosis; vii) forced spirometry: maximum inspiration and expiration maneuvers were carried out in a seated position and according to acceptable and reproducible ATS/ERS criteria (13).
The following parameters were obtained: maximum forced expiratory volume in $1 \mathrm{~s}\left(\mathrm{FEV}_{1}\right)$, peak expiratory flow (PEF), forced expiratory flow at $50 \%$ vital capacity $\left(\mathrm{FEF}_{50}\right)$, and forced inspiratory flow at $50 \%$ vital capacity $\left(\mathrm{FIF}_{50}\right)$, and the $\mathrm{FEF}_{50} / \mathrm{FIF}_{50}, \mathrm{FEV}_{1} / \mathrm{PEF}$ coefficients were calculated.

The presence of UAO was defined when the visual analysis of the FVL loops showed a flattening in the inspiratory and/or expiratory phase of the loop. According to the ATS/ERS guidelines, UAO was classified as extrathoracic (flattening in the inspiratory limb of the FVL), intrathoracic (repeatable plateau of forced expiratory flow, along with the lack of a forced inspiratory plateau), and fixed (similar flattening of both the inspiratory and expiratory portions of the FVL) (14). In order to improve sensitivity and specificity of the test, the morphological analysis of the curves was performed independently by three expert pneumologists with no prior patient clinical information. Although the FVL visual analysis was used as a means of classifying patients as having UAO along the study, $\mathrm{FEF}_{50} / \mathrm{FIF}_{50}$ and $\mathrm{FEV}_{1} / \mathrm{PEF}$ indices were subsequently evaluated in the recognition of UAO. $\mathrm{FEF}_{50} / \mathrm{FIF}_{50}>1.2$, and $\mathrm{FEV}_{1} / \mathrm{PEF}>8$ were chosen as cutoff points $(5,15)$.

The presence of TSH and free $\mathrm{T}_{4}$ was determined by means of chemi-luminescence (normal values: TSH 0.35-5.5 mU/l and free $\left.\mathrm{T}_{4} 10.3-22.7 \mathrm{pmol} / \mathrm{l}\right)$.

A CT Lx/i HI Speed machine (GE, Milwaukee, WI, USA) was used for the cervicothoracic CT study through a $3 \mathrm{~mm}$ helicoidal neck study in the area of the hard palate to the subcarinal level, while the patient was in inspiration. The images were processed with multiplane reconstructions on an Advantage console with Ewindowa Software v.4.1. (GE).

The functional respiratory tests were performed on a Horizon Systems PFT spirometer (Sensor Medic Corporation, Yorba Linda, CA, USA) which was calibrated prior to the test with a 31 syringe. No filter was used during maneuvers, and a minimal of three curves were registered according to the ATS criteria. SEPAR predicted values (15) were used.

\section{Statistical analysis}

Percentages were used for the qualitative variables in the descriptive analysis, and average and typical deviation, the mean, and the minimum and maximum values were used for the quantitative variables.

Variable comparison among the different groups with or without UAO was analyzed by bivariantly applying $\chi^{2}$ tests for the qualitative variables and Student's $t$-tests for the quantitative variables. If the latter did not fulfill the assumptions of normality, Mann-Whitney $U$ tests were performed. A significance of $5 \%$ was assumed in all the analyses. The statistical analysis was completed with the statistics package SPSS, version 18.0 (SPSS-Ibérica, Madrid, Spain). 


\section{Results}

Fifty subjects, 11 men and 39 women, median age 73.08 years (43.76-88.43), suffering from goiter with endothoracic enlargement, confirmed by CT scan, participated in the study. Reasons for initial clinical consultation included 3 cases with clinical compression symptoms, 7 detections during chest X-ray, 7 during CT scans, and 33 due to goiter. Forty-five subjects presented multinodular goiters, one presented uninodular goiter, and four presented diffuse goiter. Thirty cases exhibited normal functioning thyroids, 13 exhibited hyperthyroidism, and 7 exhibited hypothyroidism. UAO was diagnosed in 13 cases (26\%, IC 14.6-40.3\%) and 27 subjects (54\%) which suggested compression symptoms. Six patients had a medical history of chronic bronchitis, and only one of them presented UAO. The type of alteration detected on flow-volume curve according to ATS/ERS was as follows: 12 patients had extrathoracic, 0 had intrathoracic, and 1 had fixed (Fig. 1). Table 1 describes clinical characteristics, imaging test, and U/V curve results according to the presence or non-presence of UAO. No clinical or radiological variable was related to the presence of UAO. Analyses performed using the $\mathrm{FEF}_{50} / \mathrm{FIF}_{50}>1.2$ (15) and $\mathrm{FEV}_{1} / \mathrm{PEF}>8$ (5) cutoff points as an alternative UAO criteria to the FVL morphology did not provide any additional information (these results are not shown here).

\section{Discussion}

The frequency of UAO in subjects with endothoracic goiter enlargement in this study was $26 \%$, a frequency somewhat lower than those described for patients with goiter in most of the studies (1-5). Given that the endothoracic goiter enlargement present in our subjects

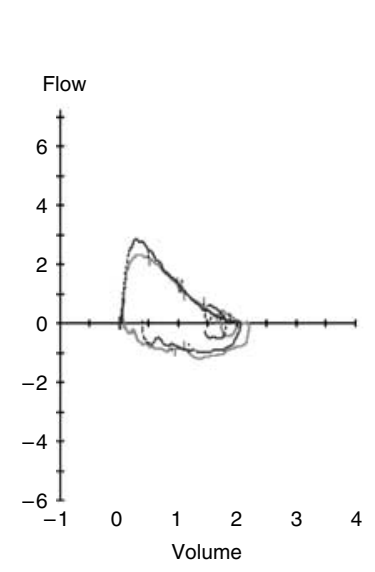

(1) Extrathoracic obstruction

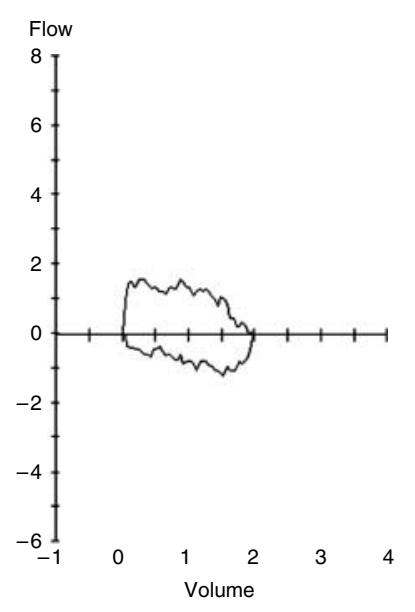

(2) Fixed obstruction
Figure 1 Morphology of the selected curves. (1) Curve with extrathoracic obstruction. (2) Curve with fixed obstruction. favors UAO, it is surprising that this percentage is so clearly lower than that described in patients with or without endothoracic goiter. Endothoracic enlargement favors the compression of mediastinal structures due to the restricted space affecting the growth of the thyroid between the sternum and the vertebra $(5,16)$. Lower percentages of UAO and the differences compared with other studies may be due to the possible smaller size of the goiters or possible lower percentage of penetration in the mediastinum. On the other hand, previous studies have not observed a relationship between the physical characteristics of the goiters, their size, or the percentage of retrosternal goiter $(2,16,17)$.

The criteria chosen for the classification of UAO may also have contributed to a lower frequency of UAO in our study. When constructing the analysis of the FVL (the most sensitive and effective method for the detection of UAO), this option was chosen as the unique criterion, and to increase sensitivity and specificity, its evaluation was limited to the concordance of three expert pneumologists.

On the other hand, another more probable cause is the performance of the forced spirometry in the seated position. The presence of UAO has been described when respiratory function studies have been done in patients lying prone, and in the same patients, these tests are not conclusive in the upright position. Meysman et al. (18) attribute it to the fact that the change in posture results in the changes in the anatomical relationship between the goiter and the trachea, due to gravity (weight of the goiter results in a more markedly extrinsic compression in the prone position than when seated, and as a result, suggested the need to realize FVL in different prone postures in order to rule out UAO) (18).

Clinical compressive symptoms were detected in 54\% of patients, results similar to a previous study (19) and lower than other studies (20), without observing the presence or non-presence of UAO, which coincides with previous results and confirms that clinical history plays little part in predicting UAO (2). The growth of a goiter is very slow and progressive, and this could explain partially why some patients with endothoracic goiters were poorly or even not symptomatic. Furthermore, tracheal cartilages ossify themselves in time and often become rigid and resist the goiter compression.

There were no differences found upon individual analysis of symptoms, although a higher tendency of dysphagia in the UAO group was present, given that dysphagia is its most frequent symptom. When we compared these results with prior studies, while a decreased frequency of dyspnea and dysphonia was observed, there was a greater presence of dysphagia (9). The presence of UAO could not be correlated with stenosis, tracheal deviation, or results of CT on tracheal compression, despite being evaluated with the visual analysis of FVL or using the ratio of cutoff points $\mathrm{FEF}_{50} / \mathrm{FIF}_{50}>1.2$ or $\mathrm{FEV}_{1} / \mathrm{PEF}>8$, described previously in the literature $(5,21)$. This is reinforced in 
Table 1 Description of subjects affected by goiter with endothoracic enlargement according to presence or non-presence of UAO, evaluated by flow-volume loops.

\begin{tabular}{|c|c|c|c|}
\hline & UAO & Non-UAO & $P$ \\
\hline Sex & $2 \mathrm{M} / 11 \mathrm{~F}$ & $9 \mathrm{M} / 28 \mathrm{~F}$ & NS \\
\hline Age (means + s.D.) & $72.2+8.35$ years & $73.2+10.11$ years & NS \\
\hline Thyroid dysfunction & $\begin{array}{l}7 \text { Normal function } \\
6 \text { Hyperthyroidism } \\
0 \text { Hypothyroidism }\end{array}$ & $\begin{array}{l}23 \text { Normal function } \\
7 \text { Hyperthyroidism } \\
3 \text { Hypothyroidism }\end{array}$ & 0.07 \\
\hline Type of goiter & $\begin{array}{l}12 \text { Multinodular } \\
0 \text { Uninodular } \\
3 \text { Diffuse }\end{array}$ & $\begin{array}{l}33 \text { Multinodular } \\
1 \text { Uninodular } \\
3 \text { Diffuse }\end{array}$ & NS \\
\hline Compressive clinical symptoms & $7 / 13(53.8 \%)$ & $20 / 37(54 \%)$ & NS \\
\hline Dysphagia & $6 / 13(46.1 \%)$ & $7 / 37(18.9 \%)$ & 0.063 \\
\hline Dyspnea & $2 / 13(15.4 \%)$ & $5 / 37(13.5 \%)$ & NS \\
\hline Dysphonia & $2 / 13(15.4 \%)$ & $2 / 37(5.4 \%)$ & NS \\
\hline Cough & $1 / 12(8.3 \%)$ & $6 / 35(17.1 \%)$ & NS \\
\hline Cervical pressure & $3 / 12(25 \%)$ & $6 / 36(17.1 \%)$ & NS \\
\hline Symptoms in prone position & $3 / 12(25 \%)$ & $4 / 36(11.1 \%)$ & NS \\
\hline Tracheal deviation $\mathrm{Rx}$ thorax & $11 / 12(91.6 \%)$ & $27 / 33(81.8 \%)$ & NS \\
\hline Tracheal stenosis Rx thorax & $5 / 12(41.6 \%)$ & $21 / 33(63.6 \%)$ & NS \\
\hline Tracheal stenosis CT & $8 / 12(66.6 \%)$ & $20 / 35(57.1 \%)$ & NS \\
\hline$\varnothing$ stenosis/ $\varnothing$ carina & $0.79(0.47-0.97)$ & $0.8(0.31-1)$ & NS \\
\hline Stenosis area/carina area & $0.85(0.33-1.23)$ & $0.86(0.33-0.99)$ & NS \\
\hline $\mathrm{FEV}_{1}$ & $1.67(0.99-2.96)$ & $1.74(0.75-4)$ & NS \\
\hline $\mathrm{FEV}_{1} / \mathrm{PEF}$ ratio & $6.68(0.6-14)$ & $6.5(4.4-10.4)$ & NS \\
\hline $\mathrm{FEF}_{50} / \mathrm{FIF}_{50}$ ratio & $1.4(0.5-2.2)$ & $0.8(0.2-4.17)$ & 0.003 \\
\hline
\end{tabular}

$\mathrm{UAO}$, upper airway obstruction; $\mathrm{CT}$, computer tomography; $\mathrm{Rx}$, simple radiology; $\mathrm{FEV}_{1}$, maximum forced expiratory volume in $1 \mathrm{~s}$; PEF, peak expiratory flow; $\mathrm{FEF}_{50}$, forced expiratory flow at $50 \%$ vital capacity; $\mathrm{FIF}_{50}$, forced inspiratory flow at $50 \%$ vital capacity.

the results of other studies $(8,22)$. Other authors have commented on the possibility that the differences are due to the fact that forced spirometry is a dynamic test normally carried out in seated or upright positions and values maximum parameters of inspiration and expiration, while the CT is a static test carried out in the prone position and in apnea after a non-maximum inspiration in which these tests could value different situations and probably they do not provide comparable information (8). On the other hand, conventional forced spirometry would not detect those cases in which UAO only manifests in prone positions; furthermore, CT carried out in inspiration could not observe the anatomical relationship which occurs in expiration situations and is one of the alterations produced in cases of endothoracic obstruction. Nevertheless, Melissant et al. (8) did not find any relationship between the FVL and tracheal measurements analyzed by CT carried out in expiration. These authors recommend evaluating other parameters such as air resistance, air conductance, and specific airways conductance which are more representative of functional worsening of unforced situations (a better reflection of daily life), although these tests require a body plethysmography and greater patient collaboration. New studies would probably be necessary to evaluate the measures of maximum inspiration and expiration CTs and to relate those results to those of spirometry performed seated and in different prone positions. The importance of finding some CT parameters which suggest the presence of UAO is because $\mathrm{CT}$ is a necessary test for diagnosing goiter with endothoracic enlargement due to its elevated sensitivity (10, 11), also for informing about the relationship between the thyroid and the other structures, and providing increased information when planning surgical treatment. This could permit having to do only one diagnostic test, eliminating the need for spirometry, a test which requires a well-informed patient and his ability to do a maximum inspiratory/ expiratory maneuver (23). Furthermore, concurrent respiratory pathology, as for example, chronic limitation of airflow, may impede the detection of UAO. Finally, it must be emphasized that this study also requires evaluation by an expert (5).

On the other hand, treatment of asymptomatic UAO subjects has been questioned (2), although studies show a postintervention improvement in FVL $(2,3,5,7,24)$. A prospective study would be necessary to evaluate the evolution of the subjects suffering from asymptomatic goiter with endothoracic enlargement and UAO in order to determine if the detection of UAO is an indication for surgery.

In conclusion, UAO in subjects with endothoracic goiter enlargement in this study is less than previously described, and there are no clinical indicators to show its presence. There is not any relationship between radiological parameters and those obtained from forced spirometry. Currently, forced spirometry remains part of the evaluation process of all goiter patients with endothoracic enlargement. In future, and based on new studies, the inclusion of more complex functional respiratory tests should be considered, or modification 
of the current procedures, as well as systematically including forced spirometry in seated and different prone positions. In any case, its role in the decisionmaking process of choosing surgical options in these patients should be reconsidered.

\section{Declaration of interest}

The authors declare that there is no conflict of interest that could be perceived as prejudicing the impartiality of the research reported.

\section{Funding}

This research did not receive any specific grant from any funding agency in the public, commercial or not-for-profit sector.

\section{Acknowledgements}

We would like to express our gratitude to Drs Montserrat Martín and Yolanda Torres for their comments which enabled us to improve the result interpretations of this article.

\section{References}

1 Argueta R \& Whitaker MD. When a thyroid abnormality is palpable: what it means and what you should do. Postgraduate Medicine 2000107 100-110. (doi:10.3810/pgm.2000.01.806)

2 Gittoes NJL, Miller MR, Daykin J, Sheppard MC \& Franklyn JA. Upper airways obstruction in 153 consecutive patients presenting with thyroid enlargement. BMJ 1996312484.

3 Thusoo TK, Gupta UG, Kochhar K \& Hira HS. Upper airway obstruction in patients with goiter studied by flow volume loops and effect of thyroidectomy. World Journal of Surgery 200024 1570-1572. (doi:10.1007/s002680010279)

4 Nygaard B, Soes-Petersen U, Hoilund-Carlsen PF, Veje A, Holst PE, Vestergaard A \& Sølling K. Improvement of upper airway obstruction after ${ }^{131}$ I-treatment of multinodular non-toxic goiter evaluated by flow-volume loop curves. Journal of Endocrinological Investigation 199619 71-75.

5 Miller MR, Pincock AC, Oates GD, Wilkinson R \& Skene-Smith H. Upper airway obstruction due to goitre: detection, prevalence and results of surgical management. Quarterly Journal of Medicine 1990 74 177-188.

6 Noppen M, Poppe K, D'Haese J, Meysman M, Velkeniers B \& Vincken W. Interventional bronchoscopy for treatment of tracheal obstruction secondary to benign or malignan thyroid disease. Chest 2004125 723-730. (doi:10.1378/chest.125.2.723)

7 Jauregui R, Lilker ES \& Bayley A. Upper airway obstruction in euthyroid goiter. Journal of the American Medical Association 1977 238 2163-2166. (doi:10.1001/jama.238.20.2163)

8 Melissant CF, Smith SJ, Perlberger R, Verschakelen J, Lammers J-WJ $\&$ Demedts M. Lung function, CT-scan and X-ray in upper airway obstruction due to thyroid goitre. European Respiratory Journal 19947 1782-1787. (doi:10.1183/09031936.94.07101782)

9 Ayache S, Mardyla N, Tramier B \& Strunski V. Signes cliniques et correlations radiocliniques dans una série de 117 goitres cervico-thoraciques. Revue de Laryngologie - Otologie - Rhinologie 2006127 229-237.
10 Hashmi SM, Premachandra DJ, Bennett AMD \& Parry W. Management of retrosternal goitres: results of early surgical intervention to prevent airway morbidity, and a review of the English literature. Journal of Laryngology and Otology $2006 \mathbf{1 2 0}$ 644-649.

11 Rodríguez JM, Hernández Q, Pinero A, Ortiz S, Soria T, Ramírez P \& Parrilla P. Subesternal goiter: clinical experience of 72 cases. Annals of Otology, Rhinology, and Laryngology 1999108 501-504.

12 Page C \& Strunski V. Cervicothoracic goitre: an anatomical or radiological definition? Report of 223 surgical cases Journal of Laryngology and Otology 2007121 1083-1087.

13 Miller MR, Hankinson J, Brusasco V, Burgos F, Casaburi R, Coates A, Crapo R, Enright P, van der Grinten CPM, Gustafsson P, Jensen R, Johnson DC, MacIntyre N, McKay R, Navajas D, Pedersen OF, Pellegrino R, Viegi G \& Wanger J. Standardisation of spirometry. European Respiratory Journal 200526 319-338. (doi:10.1183/09031936.05.00034805)

14 Pellegrino R, Viegi G, Brusasco V, Crapo RO, Burgos F, Casaburi R, Coates A, van der Grinten CP, Gustafsson P, Hankinson J, Jensen R, Johnson DC, MacIntyre N, McKay R, Miller MR, Navajas D, Pedersen OF \& Wanger J. Interpretative strategies for lung function tests. European Respiratory Journal 200526 948-968. (doi:10. $1183 / 09031936.05 .00035205)$

15 Roca J \& Sanchis J. Spirometric reference values for a mediterranean population. Bulletin Européen de Physiopathologie Respiratoire 198622 127-134.

16 Mackle T, Meaney J \& Timon C. Tracheoesophageal compression associated with subesternal goitre. Correlation of symptoms with cross-sectional imaging findings. Journal of Laryngology and Otology $2007121358-361$.

17 Karbowitz SR, Edelman LB, Nath S, Dwek JH \& Rammohan G. Spectrum of advanced upper airway obstructiob due to goiters. Chest 198587 18-21. (doi:10.1378/chest.87.1.18)

18 Meysman M, Noppen M \& Vincken W. Effect of posture on the flow-volume loop in two patients with euthyroid goiter. Chest 1996110 1615-1618. (doi:10.1378/chest.110.6.1615)

19 Cho HT, Cohen JP \& Son ML. Management of subesternal and intrathoracic goiters. Otolaryngology and Head and Neck Surgery $198694282-287$.

20 Erbil Y, Bozbora A, Barbaros U, Ozarmagan S, Azezli A \& Molvalilar S. Surgical managenent of subesternal goiters: clinical experience of 170 cases. Surgery Today 200434 732-736. (doi:10.1007/s00595-004-2823-4)

21 Torchio R, Gulotta C, Perboni A, Ciacco C, Guglielmo M, Orlandi F \& Milic-Emili J. Orthopnea and tidal expiratory flow limitation in patients with euthyroid goiter. Chest $2003 \mathbf{1 2 4} 133-140$. (doi:10. 1378/chest.124.1.133)

22 Demedts M, Melissant C, Buyse B, Verschakelen J \& Feenstra L. Correlation between functional, radiological and anatomical abnormalities in upper airway obstruction (UAO) due to tracheal stenosis. Acta Oto-Rhino-Laryngologica Belgica 199549 331-339.

23 Jordanoglou J \& Pride NB. A comparison of maximum inspiratory and expiratory flow in health and in lung disease. Thorax 196823 38-45. (doi:10.1136/thx.23.1.38)

24 Geraghty JG, Coveney EC, Kiernan M \& O’Higgins NJ. Flow volume loops in patients with goiters. Annals of Surgery 1992215 83-86. (doi:10.1097/00000658-199201000-00013)

Received 9 July 2010

Accepted 5 August 2010 